\title{
Data Flow Diagrams of an Electronic Medical Record System in Mansoura Hospital
}

\author{
Ali A. Sakra, and Diana T. Mosa \\ Department of Computer Engineering, Faculty of Engineering, Kafr El-Sheikh University, Egypt \\ ali_asakr@yahoo.com, ali_asakr@eng.kfs.edu.eg \\ Department of Mathematical, Faculty of Science, Mansoura University, Egypt \\ dianamosa@sci.man.edu.eg
}

\begin{abstract}
This paper develops an Electronic Medical Record System in the Neurosurgical Unit of Mansoura General Hospital using Data Flow Diagrams. Data Flow Diagrams are the first step to design the system blueprint as they represent user's requirements. The paper creates a "context-aware" fisheye view as it is more successfully communicate the information contained in a set of Data Flow Diagrams (DFD) than a traditional "context-free" presentation. A case study and experimental results show that our context-aware" fisheye DFD's are well suited for application in developing Electronic Medical Record System. This makes the expert system more reliable and faster response.
\end{abstract}

\section{Keywords:}

DFD; Fisheye View; Electronic Medical Record System (EMRS); Graphic User Interface (GUI).

\section{INTRODUCTION}

Medical databases are designed specifically to manage large amount of data, and they store data in an organized and structured manner that makes it easy for users to manage and retrieve data when required [1]. These data types may be text or video forms. All data that concerns the patient history, and his laboratory imaging- tests are stored in DBS. Authorized users (doctors, nurses, employees) have a right to access and modify the contents of the DB according to their role in the system. As the quality of any medical treatment depends on the accurate processing of multiple complex components of information, Physicians need to access to the patient records to develop skills in using and maintaining any clinical record, gain experience of entering data onto clinical records [8]. EMRS are now being increasingly employed to collect and synthesize medical information. The EMRS offers support in medical decision making, coordination between different healthcare providers and improves the overall quality of care. It will improve health care by decreasing redundancy and cost [3,11], and reducing the likelihood of treatment errors [2, 7]. This paper presents the EMRS for Neurosurgical unit in Mansoura General Hospital (MGH). A complete EMRS is complex and has many components [4]. A critical component of the EMRS is the backend DB system, which will manage the neurosurgical unit's data. Before, the design and implementation of the DB, the requirements can be gathered by interviewing both the producer and the user of the data; this process helps in creating a formal requirement specification [3]. The development of the neurosurgical unit database is integrated into Data Flow Diagrams (DFDs). DFDs are graphical representations of data flow models for designing complex systems [14]. The analysts use DFDs for drawing graphical representations of the user's requirements. This diagram establishes the boundary of a process by showing the flow of data from external entities into the system and from one process to another within the system $[1,10]$. DFDs also are used for software requirements specification and modeling of the interaction between processes and data [14].

This paper, use a visualization technique called the fisheye views for systems analysis and design diagrams. Fisheye presentations provide greater continuity between details and context than traditional representations. So, the users would have a better understanding of the processes in those diagrams and this would lead to more effective analysis of a system in less time. The effective fisheye representations of DFDs would need expansion of a portion of a higher-level diagram without causing confusion to the rest of the display. It gives a good overall picture of the whole GUI system and an easy look at each process, it allows embedding a lower level process diagram within its parent [12]. This paper is organized as follows: section 2 presents the search methodology which includes a quick overview of DFD orientation and indicates the aims of using it in presenting medical record system processes in neurosurgical unit. In section 3 , we present the main concepts of DFD, how details can be presented with context, and how to establish Data Dictionary (DD). In section 4, we implement DFDs, introduce the proposed DFDs for EMR, and described DD for one of the input data flow which appeared in DFDs.

\section{RESEARCH METHODOLOGY}

\subsection{Neurosurgical unit overview}

The neurosurgical unit is a clinical unit receives patients have some type of neurological problem which affect any portion of the nervous system including the brain, spinal cord, peripheral nerves, and extra-cranial cerebrovascular system, and provides them with complex neurological care. Visiting the neurosurgical unit in MGH and meeting members of the unit and some of the individuals who are responsible of dealing with unit data , this allowed us to define the problem which was represented in the current EMRS for the unit. The Unit suffers from lack of efficiency of the current EMRS that accumulate the massive amount of medical information that is difficult to search through and to retrieve data from it. After identifying the nature of the problem that face the neurosurgical unit, it was appeared that a development is needed for the current system of the unit in order to store all patient s' details without occurrence of data multiplicity. This simplifies the process of retrieving data at any time. The importance of this record originates from saving all patients' information during all 
investigations. Diagnosis, treatment, following up reports, and important medical decisions are stored to provide the best treatments for the patient.

\subsection{Data Collection}

After identifying stakeholders that is involved in the study. The data collection techniques are summarized as interviewing the members of the neurosurgical unit, examining the documentations and assuring the homogeneity of images during the observation period. Neurosurgical unit has medical team consists of many doctors and nurses. The medical team is responsible for the day running of the unit, according to shifts which determines the responsibility of working inside the unit. When a new medical member joins the unit, he/she registers his/her personal details, qualifications (BSc. MSc., Ph.D.), rank (Consultant, Specialist, Resident, House Offices, High Nurse, Nurse), and specialty (Neurosurgeon, Anesthesiologist, Intensive Care Unit Specialist, Neurologist, ..). The unit receives patients from different sources, emergency, external clinic, or another hospital. It receives a number of patients and keeps track of each patient's personal data: ID, name, national ID, address, blood group, sex, birthdate, occupation, social status, nationality, religion, communication mean (home telephone, or mobile) and special habits (smoking, or drugs). It also needs to refer to the city, country, and governorate. Both patient ID and national ID have the same values for each patient. Patient may have many visits for the unit, and each visit is identified using the admission number, admission time and date. After referring the patient to the unit, the receptionist must request the patient to complete his/her personal details. Patient will determine the admission type (Emergency, Insurance, Nation Expense, Treatment with Fee, and Free treatments), and referral source (emergency, external clinic, or others). Then Patient starts to fill a number of consents like approval consent of hospital entrance, treatments reception, blood transfusion, and smoking giving up, and approval consent of receiving medical treatments with fees. These consents require existence of one of patient's relatives and a witness for high risk consent. A patient will requested to meet the doctor who receives patient's history (personal history: present history, past history, family history, and social history). Doctor does several the examinations to determine some medical signs. To assist in the diagnosis, doctors ask the patient to do some investigations (Laboratory, Neuro- physilogical, Radio-logical, and Histopathological) which will be necessary in determining diagnosis and treatment plan (Medical, Surgery, Radiosurgery, Radiotherapy, and Chemotherapy). If it is decided to treat patient with surgery, neurosurgical unit must keep track of anesthetic technique and operative details (operation's type, anesthesia type, position, skin incision, operative steps, intraoperative complications, and closure). Medical team follows up patients clinically and radio-logically. At the end of treatment stage, the doctors reexamine the patient to determine final diagnosis. The unit evaluates treatment plan to ensure of the success of treatment plan and to process weak points in next times. Patient's visit finishes with the determination of patient's discharge state (recovery, improvement, no improvement, death), and patient's discharge type (discharge according to the patient desire, discharge due to a clinic, discharge to another hospital) and discharge date.

Table 1. Collected Documents of the Neurosurgical unit

\begin{tabular}{|c|c|c|c|c|c|c|}
\hline No & Document & Source & Destination & Usage & Rate & Contents \\
\hline 1 & external clinic ticket & external clinic & neurosurgical unit & $\begin{array}{l}\text { collects } \\
\text { data for } \\
\text { patient }\end{array}$ & $\begin{array}{l}\text { patient } \\
\text { enters } \\
\text { external } \\
\text { clinic }\end{array}$ & $\begin{array}{l}\text { patient name, clinic name, } \\
\text { reservation appointment }\end{array}$ \\
\hline 2 & emergency ticket & $\begin{array}{l}\text { emergency } \\
\text { receptionist }\end{array}$ & neurosurgical unit & $\begin{array}{l}\text { collects } \\
\text { data for } \\
\text { patient }\end{array}$ & $\begin{array}{l}\text { patient } \\
\text { enters } \\
\text { emergency } \\
\text { unit }\end{array}$ & $\begin{array}{l}\text { emergency ticket no, } \\
\text { patient name, sex, age, } \\
\text { social status, address, } \\
\text { referral department, } \\
\text { arrival time and date, } \\
\text { discharge time and date, } \\
\text { level of consciousness, } \\
\text { arrival type of accident }\end{array}$ \\
\hline 3 & hospital's consent & relative & doctor & $\begin{array}{l}\text { consent of } \\
\text { patient, } \\
\text { approval to } \\
\text { enter the } \\
\text { hospital, } \\
\text { blood } \\
\text { transfusion, } \\
\text { approval of } \\
\text { medical } \\
\text { treatments }\end{array}$ & $\begin{array}{l}\text { for every } \\
\text { patient } \\
\text { admission } \\
\text { to the unit }\end{array}$ & $\begin{array}{l}\text { patient name } \\
\text { patient address } \\
\text { patient ID, relative name, } \\
\text { relative address } \\
\text { relative ID, } \\
\text { doctor name, }\end{array}$ \\
\hline 4 & high risk consent & witness & doctor & $\begin{array}{l}\text { consent of } \\
\text { the patient, } \\
\text { approval to }\end{array}$ & $\begin{array}{l}\text { decided for } \\
\text { the patient } \\
\text { to treat with }\end{array}$ & $\begin{array}{l}\text { patient name, } \\
\text { patient address, }\end{array}$ \\
\hline
\end{tabular}




\begin{tabular}{|c|c|c|c|c|c|c|}
\hline & & & & surgery & surgery & $\begin{array}{l}\text { patient ID, witness name, } \\
\text { witness address, } \\
\text { witness ID, time, } \\
\text { doctor name }\end{array}$ \\
\hline 5 & $\begin{array}{l}\text { referral letter from } \\
\text { another hospital }\end{array}$ & $\begin{array}{l}\text { another } \\
\text { hospital }\end{array}$ & neurosurgical unit & $\begin{array}{l}\text { allows to } \\
\text { patient } \\
\text { admission }\end{array}$ & $\begin{array}{l}\text { patient is } \\
\text { referred } \\
\text { from } \\
\text { another } \\
\text { hospital }\end{array}$ & $\begin{array}{l}\text { hospital name, patient } \\
\text { name, age, address, } \\
\text { referral time, diagnosis, } \\
\text { referral reason, } \\
\text { patient's aids, } \\
\text { doctor name }\end{array}$ \\
\hline 6 & medical report & $\begin{array}{l}\text { neurosurgical } \\
\text { unit }\end{array}$ & gov. agencies & $\begin{array}{l}\text { comments } \\
\text { according } \\
\text { to patient } \\
\text { status }\end{array}$ & $\begin{array}{l}\text { when } \\
\text { required }\end{array}$ & $\begin{array}{l}\text { gov. agencies name, } \\
\text { patient name, } \\
\text { hospital admission date, } \\
\text { admission no., } \\
\text { recommendations, } \\
\text { discharge date, doctor } \\
\text { name, hospital name, }\end{array}$ \\
\hline 8 & follow up card & $\begin{array}{l}\text { neurosurgical } \\
\text { unit }\end{array}$ & patient & Flow up & $\begin{array}{l}\text { Number of } \\
\text { investigation } \\
\mathrm{s}\end{array}$ & $\begin{array}{l}\text { patient ID, patient name, } \\
\text { admission date, age, } \\
\text { sex, address, diagnosis, } \\
\text { discharge, treatment, } \\
\text { follow up, appointment, } \\
\text { doctor name, }\end{array}$ \\
\hline 9 & $\begin{array}{l}\text { referral letter to } \\
\text { another hospital }\end{array}$ & $\begin{array}{l}\text { neurosurgical } \\
\text { unit }\end{array}$ & another hospital & $\begin{array}{l}\text { continue } \\
\text { treatment in } \\
\text { another } \\
\text { hospital }\end{array}$ & $\begin{array}{l}\text { patient will } \\
\text { continue } \\
\text { treatment in } \\
\text { another } \\
\text { hospital }\end{array}$ & $\begin{array}{l}\text { hospital name, patient } \\
\text { name, age, address, } \\
\text { referral time, diagnosis, } \\
\text { patient's aids, doctor } \\
\text { name, }\end{array}$ \\
\hline 10 & analysis and images & $\begin{array}{l}\text { investigation } \\
\text { laboratory }\end{array}$ & doctor & $\begin{array}{l}\text { contain } \\
\text { investigatio } \\
\mathrm{n} \text { results }\end{array}$ & $\begin{array}{l}\text { doctor } \\
\text { order } \\
\text { according } \\
\text { to } \\
\text { diagnosis }\end{array}$ & $\begin{array}{l}\text { laboratory name, lab. no. } \\
\text { patient name, patient } \\
\text { code, age, sex, ticket no, } \\
\text { location, request date, } \\
\text { reporting date, } \\
\text { investigation type, } \\
\text { investigation result, } \\
\text { report date, }\end{array}$ \\
\hline 11 & patient's visit report & $\begin{array}{l}\text { neurosurgical } \\
\text { unit }\end{array}$ & neurosurgical unit & $\begin{array}{l}\text { gives } \\
\text { required } \\
\text { report for } \\
\text { patient } \\
\text { case }\end{array}$ & $\begin{array}{l}\text { at the end } \\
\text { of patient } \\
\text { visit }\end{array}$ & $\begin{array}{l}\text { patient name, admission } \\
\text { date, admission no., } \\
\text { admission diagnosis, } \\
\text { treatment plan, final } \\
\text { diagnosis, discharge date, } \\
\text { doctor name }\end{array}$ \\
\hline 12 & emergency's report & $\begin{array}{l}\text { neurosurgical } \\
\text { unit }\end{array}$ & police & $\begin{array}{l}\text { gives report } \\
\text { for patient } \\
\text { case }\end{array}$ & $\begin{array}{l}\text { when } \\
\text { required }\end{array}$ & $\begin{array}{l}\text { patient name, hospital } \\
\text { admission date, } \\
\text { admission no., admission } \\
\text { case, discharge case, } \\
\text { discharge date, doctor } \\
\text { name, hospital name }\end{array}$ \\
\hline
\end{tabular}




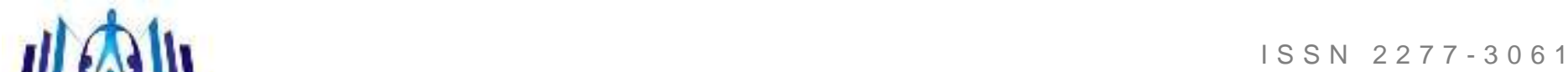

International journal of Computers and Technology

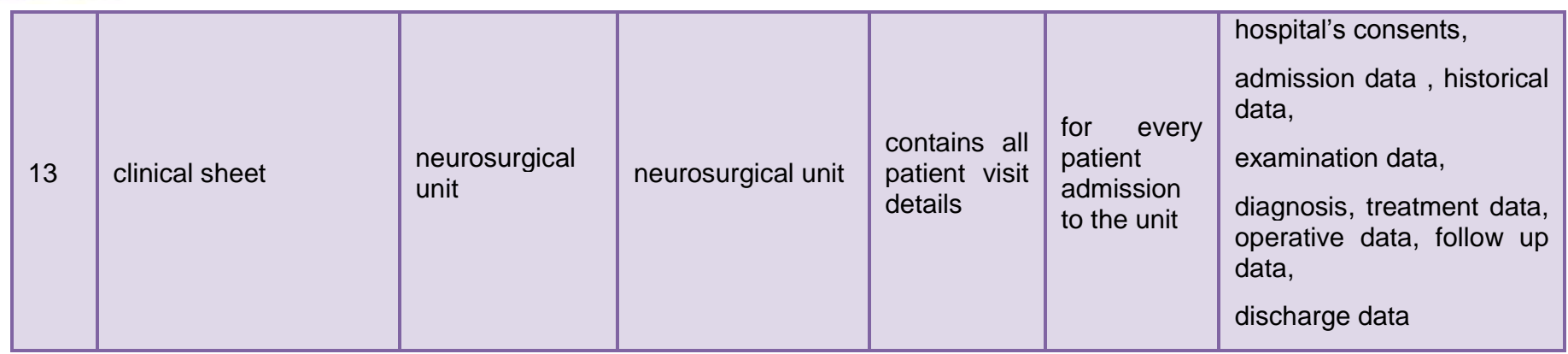

After completing and documenting system requirements, the DB design phase starts. Design the logical structure of an information system defines all the information required by the user and required for the efficient behavior of the whole information system for all users.

\subsection{Overview of the DFD's}

DFDs are the cornerstones for structured system analysis and design, which is considered a document that can be shown to analysts and designers. DFD enables tram to start at any point in the operation (e.g., admission of patient, diagnosis, determine treatment plan). The treating team can understand the processing steps that the neurosurgical unit would need to take to complete the relevant transactions. DFD makes it possible to understand what data are needed to provide appropriate inputs to any processing step. This technique is strongly hierarchical and the context is readily available and commonly used and thus remains a useful tool for the process improvement [2]. In this section we will briefly overview the general characteristics of DFDs.

Data flow and data stores should receive names that describe the composition of the data flowing through the system. External entities should receive names that describe the sources and destinations of the data. Process symbols should be named with strong verbs to indicate the basic transformation or process that is taking place [10, 12] as shown in Figure 2.
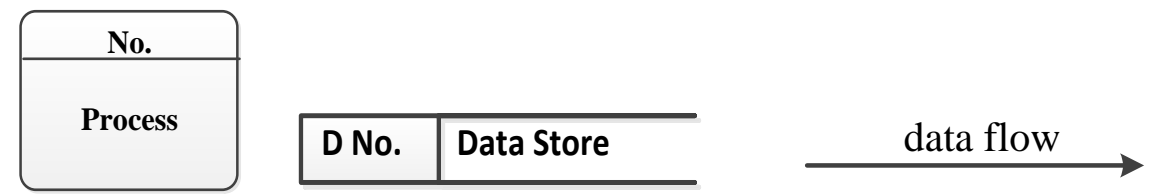

\section{External Entity}

\section{Figure 1. The Main Components of DFD.}

DFD can be leveled to its functional primitive [1]. The detailed DFD provides a more detailed and comprehensive view of the interaction among the sub-processes within the system [9]. The Context Diagram is the starting point, which defines the scope of the system. For the Top-Level (Level 0), DFD provides a more detailed description of the system. DFD is used to describe, the overall processing in the system. The scope of the system presented in this level remains the same as in the context diagram. The difference is that the single and central process, will be partitioned into a series of components, or major subsystems within overall system. Level 1-DFD expands the processes in the level 0 diagram basically.

\subsection{Viewing the Details by Means of a Fisheye View}

Fisheye views are visualization technique that present system processes by embedding process details and context within the same diagram. Fisheye view presents relationships between subprocesses, their parent processes and the other processes in a system more effectively, so it will be helpful in understanding theses concepts in DFDs. Bederson [12] developed fisheye menus as an alternative to the traditional hierarchical view and found that this technique was preferred by users for general browsing as in Figure 2 .

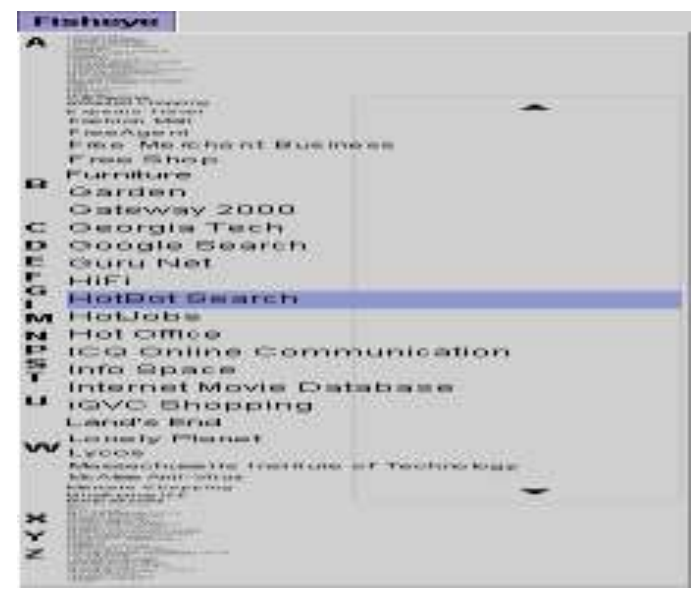

Figure 3. Fisheye menu. 


\section{DISCUSSIONS and RESULTS}

In structured modeling, the primary priority is given for the various processes in the system domain. The system is analyzed as functional processes and each process is designed and implemented accordingly. The DFD is a hierarchical set of diagrams; each diagram in the set is a decomposition of the preceding diagram. The starting point in designing DFDs is the context diagram, which defines the scope of the system. It highlights the net inputs and sources as well as the net outputs and destinations of data for the system. In this level, the scope of the system is represented as one process. We show all external entities, which interacted with the system and all data flows between these and the system. The purpose of the context diagram is to depict how the system is connected to other entities that make its data environment. Figure 4 is the context diagram of EMRS. It illustrates seven external entities are served as client and server according to the direction of the data flow. The type of data involved in each dataset along the data flow is recorded.

The second level in DFDs is "level 0 diagram", which provides a more detailed description of the system. It is used to describe the overall processing in the system. The scope of the presented system in this level remains the same as in the context diagram. The difference is that the single and central processes for the entire system, will be partitioned into major subsystems within overall system.

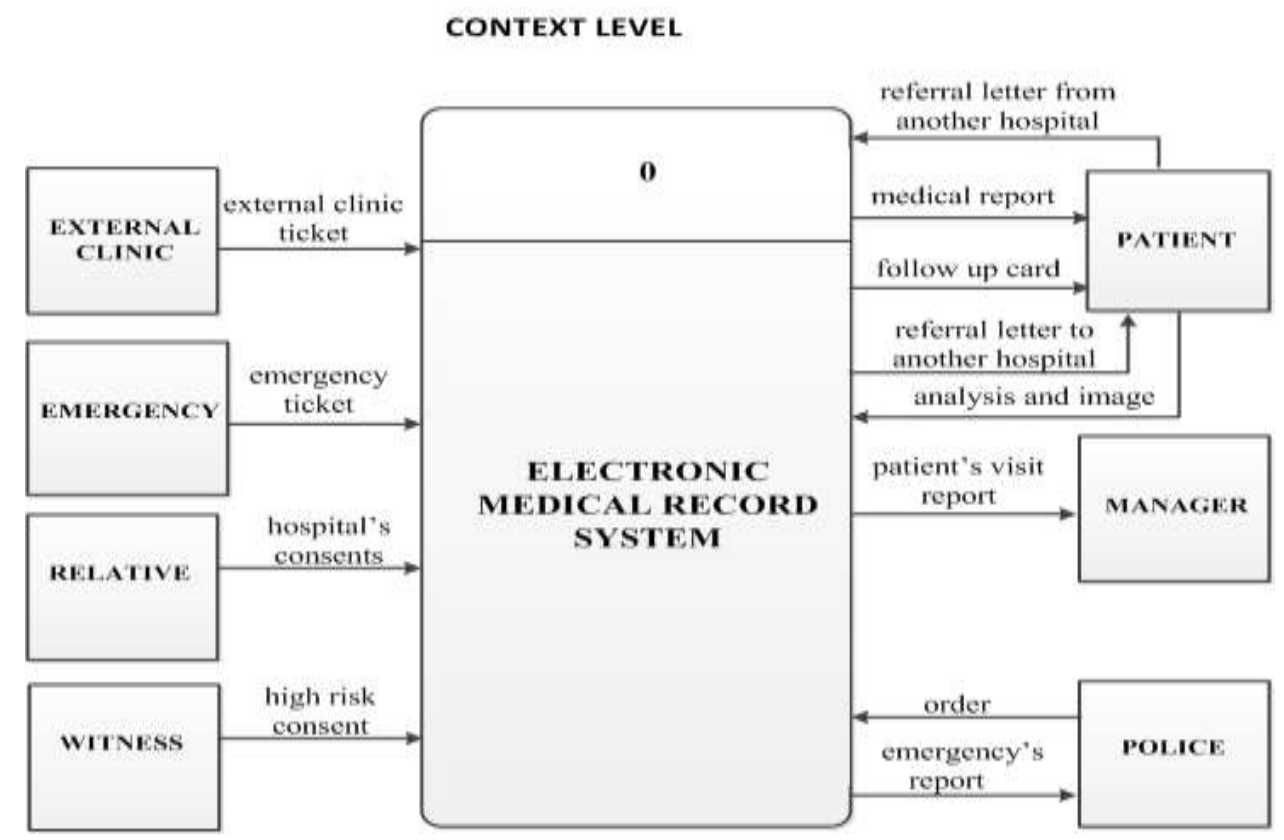

Figure 3 The context diagram of EMRS.

Level 0 diagram still has the same seven external entities. This level of DFD starts by:

1- Making a list of the major data stores currently in use like: Patient which contains all patient personal data, Admission which contains all patient admission data, and Documents which contains all papered documents.

2- Listing the major business occurrences or events within the system like:

- Admission of Patient which collects all admission data (patient admission data, and data for medical team who is responsible for patient admission),

- Diagnosis which represents (identifying patient complaint, patient check and doing required investigations which will be helpful in determining the diagnosis),

- Treatment Plan in which treatment type is determined. allows registering the anesthesia and operation data, and

- Discharge of Patient which registers discharge data and generates required reports for patient visit.

3- Drawing a segment, or fragment, of a DFD for each of the identified events.

4- Assembling the fragments into a single DFD as illustrated in Figure 5.

The third level in DFDs is " level 1 diagrams", which expands the processes in the level 0 diagram basically and gives detailed and comprehensive view of the EMRS. The paper introduces two different presentations of level 1 of DFDs system processes: traditional and fisheye presentations, which include different degrees of contextual information. Figure. 6. shows traditional presentation which indicates what data are needed to provide appropriate inputs to any processing step. This type of presentation shows separate view for system processes. The plant DB's necessitates search time proportional to " $n$ ", the number of entities. Using two level databases reduces the effective number of entities to square root of $n$, which improves data acquisition rate, and improve the response time of expert system. 
In this study, using the fisheye visualization technique of the DFDs is more successful than traditional plan views. It allows embedding the details of the process within their context by showing elements directly connected to the elements of an expanded sub-process as well as the elements connected to the directly connected elements. It enables us to understand system processes more completely as it was easier to look at each process in depth by zooming in on areas. The fisheye technique provides greater continuity between details and context than traditional representations, we prefer to use it to present level 1 of DFDs system processes.

Decomposing the DFDs is stopped, as reaching enough detail and the processes describe simple tasks and cannot be decomposed any further. DFDs achieved the consistency, and the balance is kept between all child diagrams and processes decomposed from father diagram. The completeness as each process in DFD must have input and output flows.

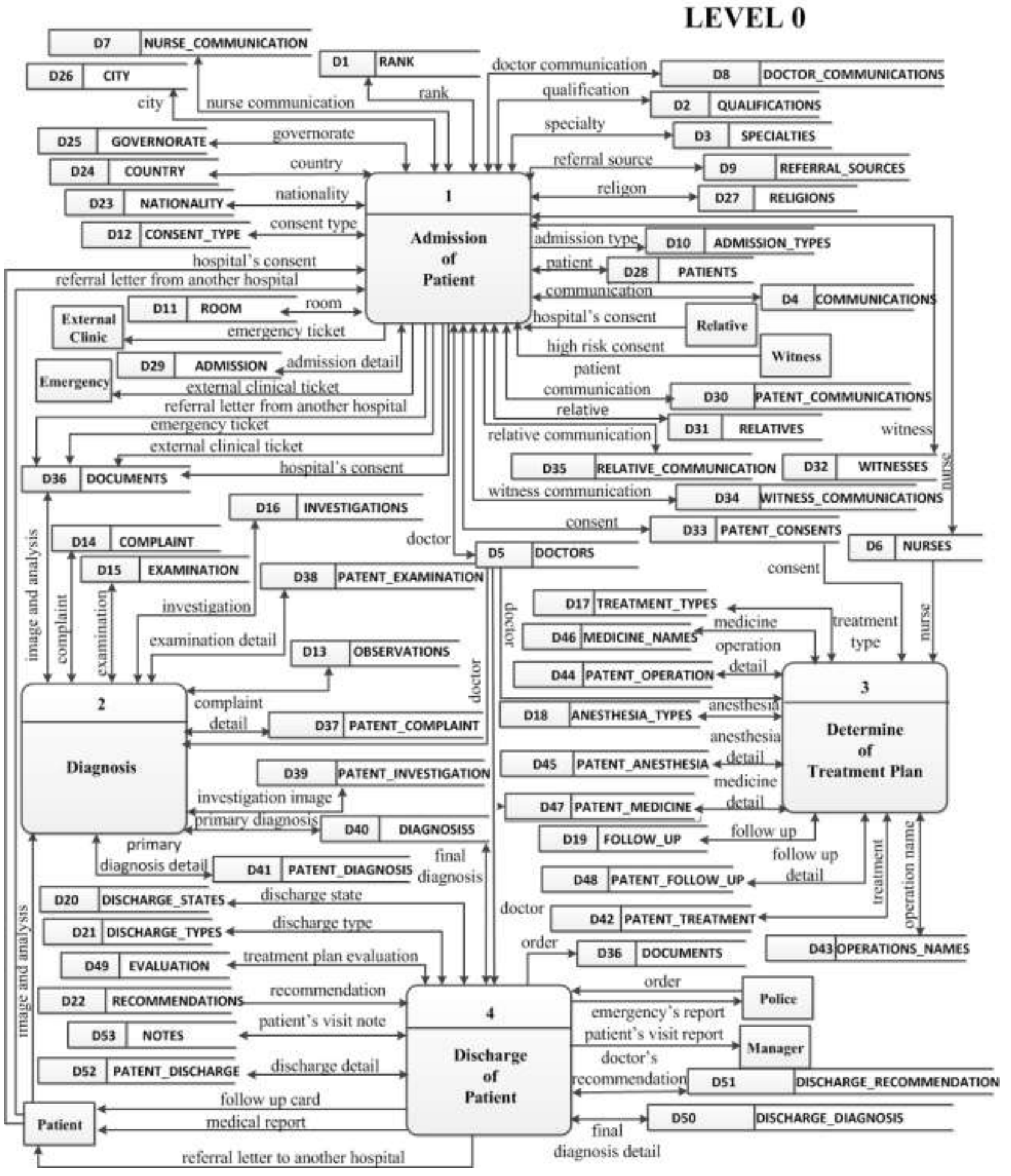

Figure 4. Level 0 Diagram of EMRS. 
Figure. 7 views the details of process 1 separately from the context. Figure 7, shows fisheye view presentation which demonstrate the presentation of medical record system processes by integrating process details and context within the same diagram. It accomplishes this by showing elements directly connected to the elements of an expanded subprocess as well as the elements connected to those directly connected elements. Figure 7, Figure 8, Figure 9, and Figure 10; View the details of process 1, 2, 3 and 4 respectively, by means of a fisheye view.

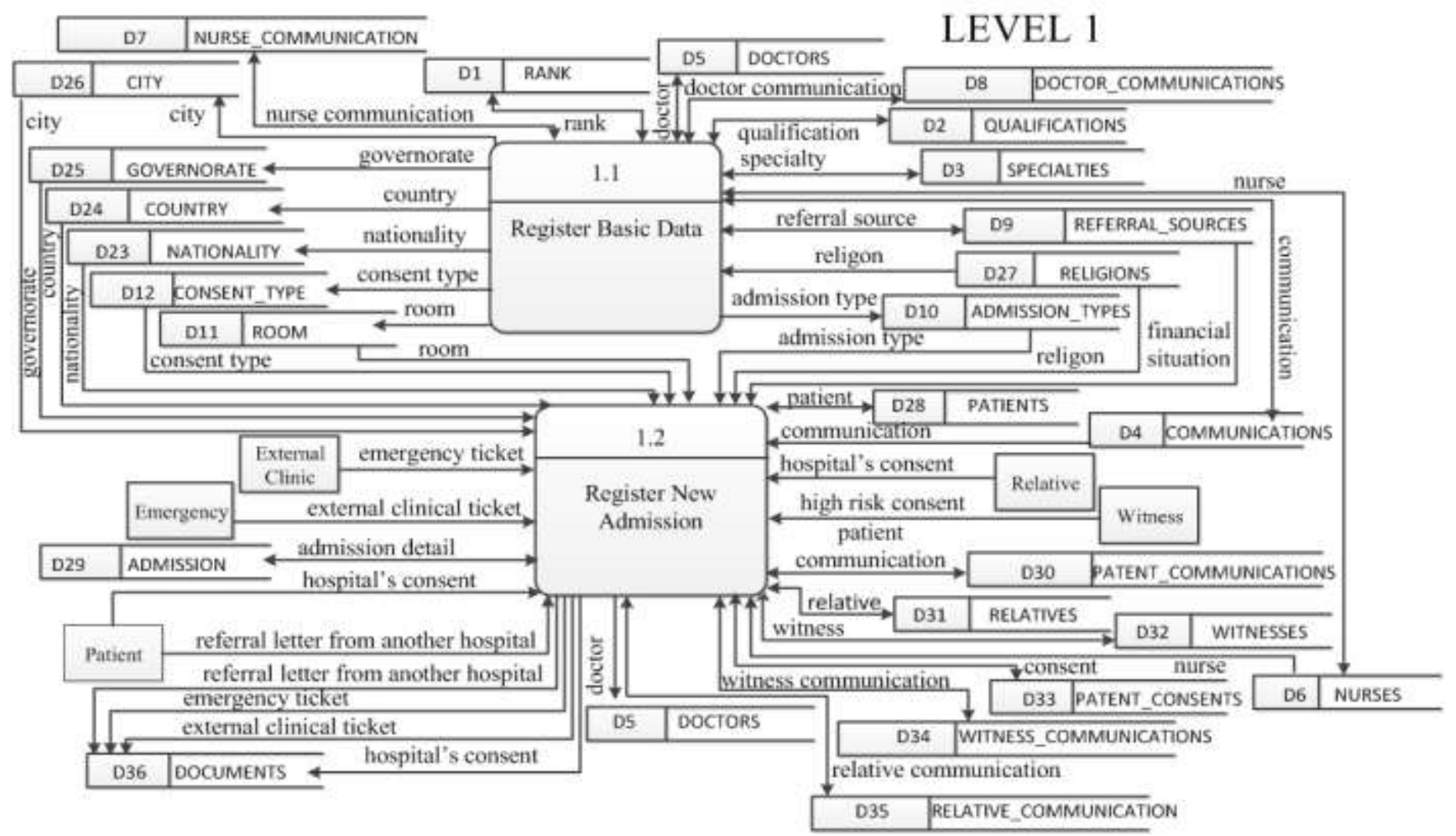

Figure 5. Viewing the details of process 1 separately from the context.

By recalling Figure 5, To define the input data flow admission detail (DD). By applying the first rule, the input data flow might typically be defined as follows:

Admission $=$ Patient ID + Referral Source + Patient First Name + Patient Middle Name + Patient Family Name + Patient_Date_of_Birth + Patient_Sex + Patient_Social_Status + Patient_Nationality + Patient_National_ID + Patient_Blood_Group + Patient_Occupation + Patient_Religion + Patient_Address + Patient_City + Patient_Governorate + Patient_Country + Patient_Phone_Home + Patient_Mobile + Emergency_Contact + Emergency_Contact_Relation + Emergency_Contact_Address + Emergency_Contact_Phone + Patient_Special_Habits + Admission_No +

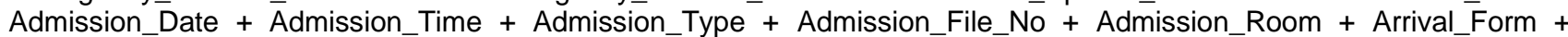
Type_of_Accident + Admission_Level_of_Consciousness + Consciousness_Duration +

Admission_History + Admission_Medical_Group

By applying the second rule, the elementary data elements are characterized as:

Patient_ID

Referral_Source

Patient_First_Name

Patient_Middle_Name

Patient_Family_Name

Patient_Date_of_Birth

Patient_Sex $=\quad\{$ Number $\}$

$=\quad[$ Emergency/ External Clinical/ Others $]$

$=\{$ Varchar2 $\}$

$=\quad(\{$ Varchar2 $\}),{ }^{* *}$ neurosurgical unit may receive a patient admitted by emergency unit.

$=\quad\{$ Varchar2 $\}$

$=\quad$ (Date)

$=\quad[$ Male/Female $]$ 
Patient_Social_Status

Patient_Nationality

Patient_National_ID

Patient_Blood_Group

Patient_Occupation

Patient_Religion

Patient_Address

Patient_City

Patient_Governorate

Patient_Country

tient_Phone_Home

Patient_Mobile

Emergency_Contact

Emergency_Contact_Relation

Emergency_Contact_Address

Emergency_Contact_Phone

Patient_Special_Habits

Admission_No

Admission_Type

Admission_File_No

Admission_Room

Arrival_Form

Type_of_Accident

Admission_Level_of_Consc iousness

Consciousness_Duration

Admission_History

Admission_Medical_Group $=\quad([$ Child/Single/Married/Divorced/Widowed $])$

$=\quad\left({ }^{* *}\right.$ All Nationalities, Self Defining $)$

$=(\{$ Number $\})$

$=([\mathrm{A}-/ \mathrm{A}+/ \mathrm{B}-/ \mathrm{B}+/ \mathrm{Ab}-/ \mathrm{Ab}+/ \mathrm{O}-/ \mathrm{O}+])$

$=\quad\left({ }^{* *}\right.$ All Occupations, Self Defining $)$

$=\quad\left({ }^{* *}\right.$ All Religions, Self Defining $)$

$=(\{$ Varchar2 $\})$

$=(\{$ Varchar2 $\})$

$=(\{$ Varchar2 $\})$

$=(\{$ Varchar2 $\})$

$=(\{$ Number $\})$

$=(\{$ Number $\})$

$=(\{$ Varchar2 $\})$

$=\quad[$ Son $/$ Daughter $/$ Father/Mother $/$ Husband $/$ Wife/Brother $/$ Sister $]$

$=(\{$ Varchar2 $\})$

$=(\{$ Number $\})$

$=(\{$ Varchar2 $\})$

$=\quad\{$ Number $\}$

$=\quad[$ Emergency/Insurance/Nation Expense/Treatment With Fee/Free $]$

$=\quad\{$ Number $\}$

$=\quad\{$ Varchar2 $\}$

$=\quad[$ Alone/Ambulance/Police/Others $]$

$=\quad[$ R.T.A/School/Self Infected/Home/Assault/Specify/Work/Others $]$

$=\quad[$ Fully Consciousness \& Oriented/Respond To Painful Stimuli/ Respond To Questions/Unconscious]

$=\quad$ Time

$=\quad\{$ Varchar2 $\}$

$=\{$ Varchar2 $\}$ 


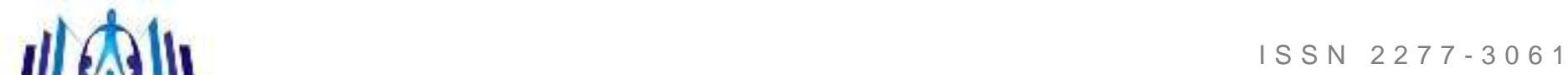

Volume $15 \mathrm{Number} 7$

International journal of Computers and Technology

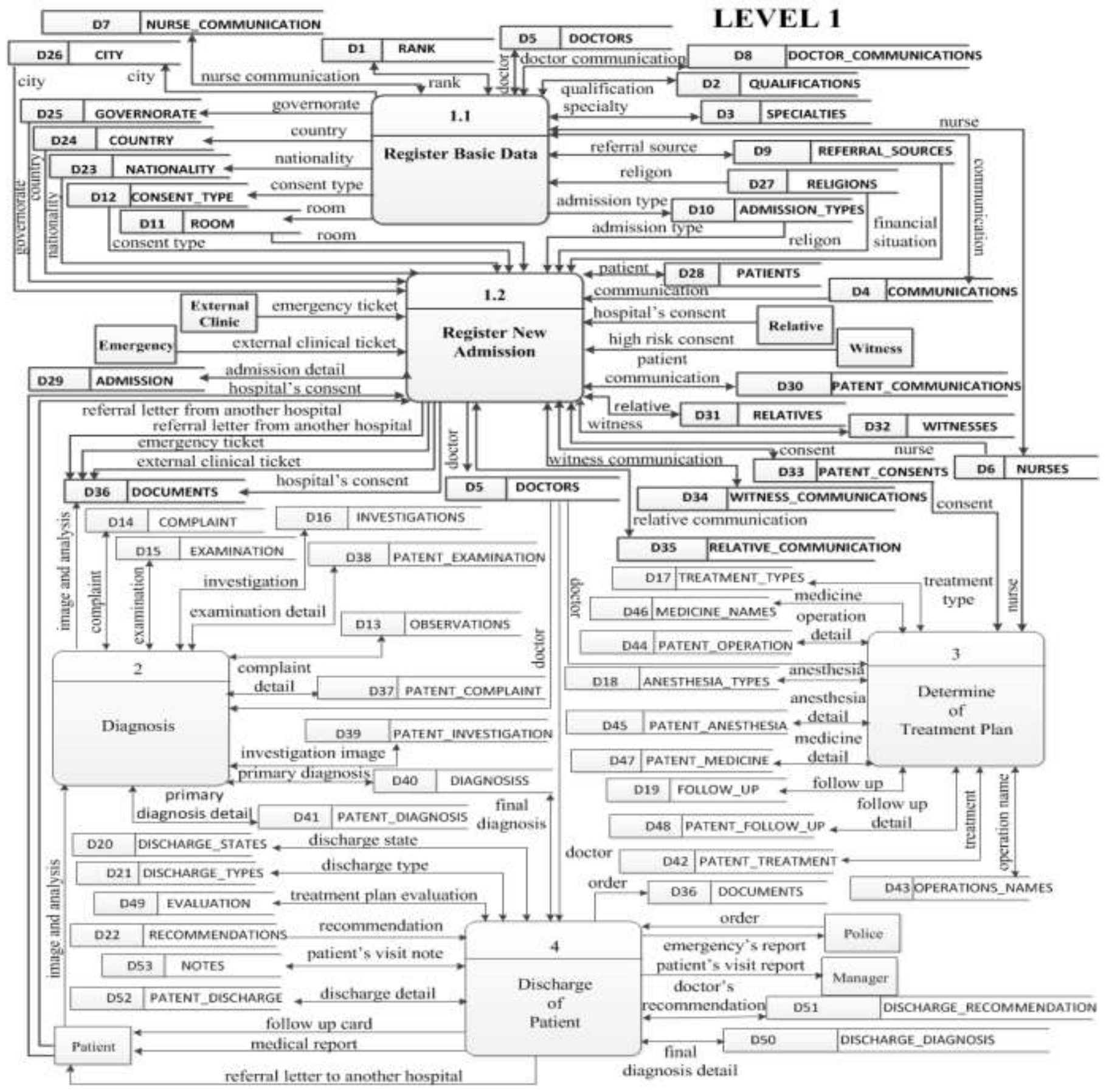

Figure 6 Viewing the details of process 1 by means of a fisheye view. 


\section{LEVEL 1}

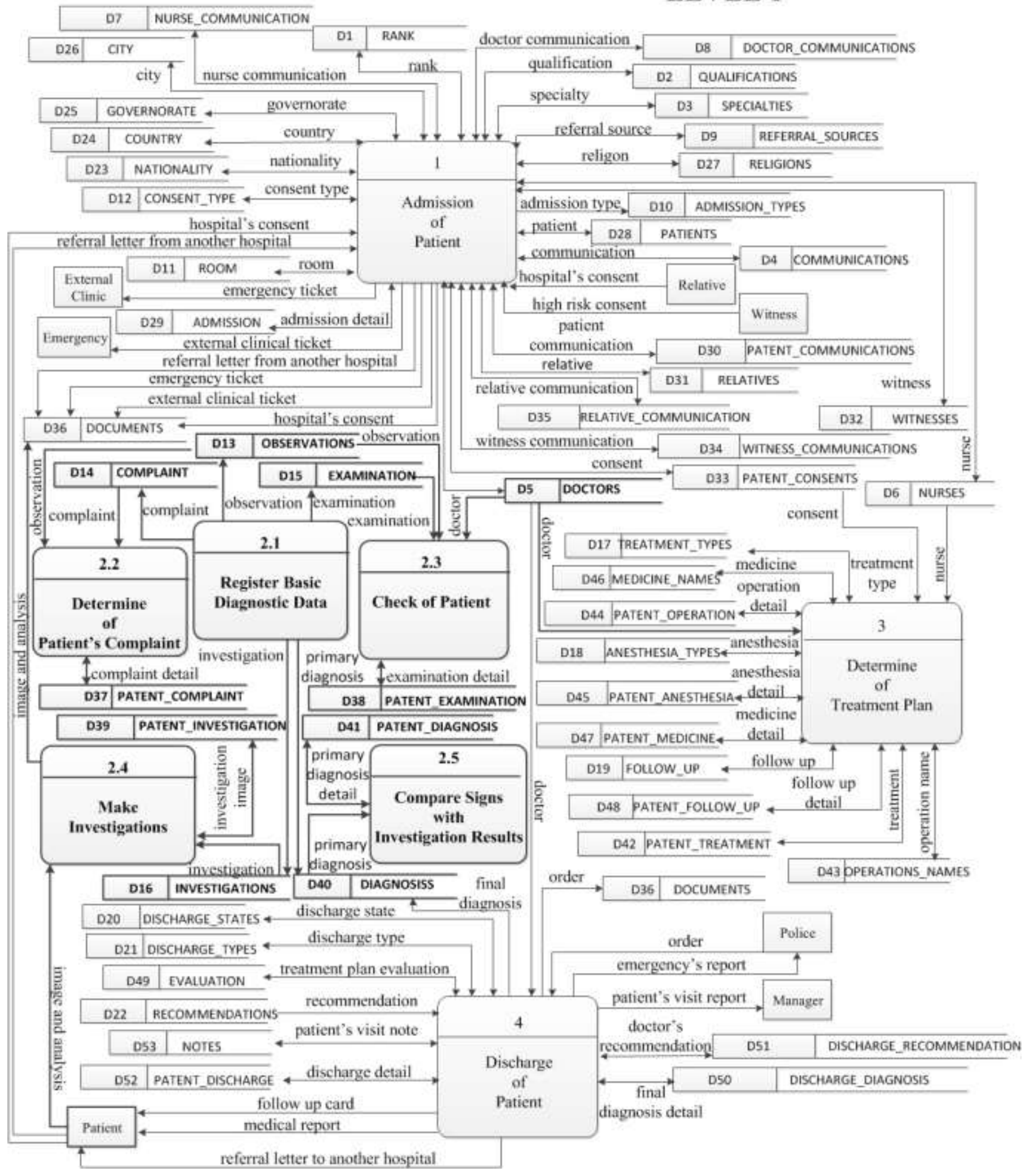

Figure 7 Viewing the details of process 2 by means of a fisheye view. 


\section{LEVEL 1}

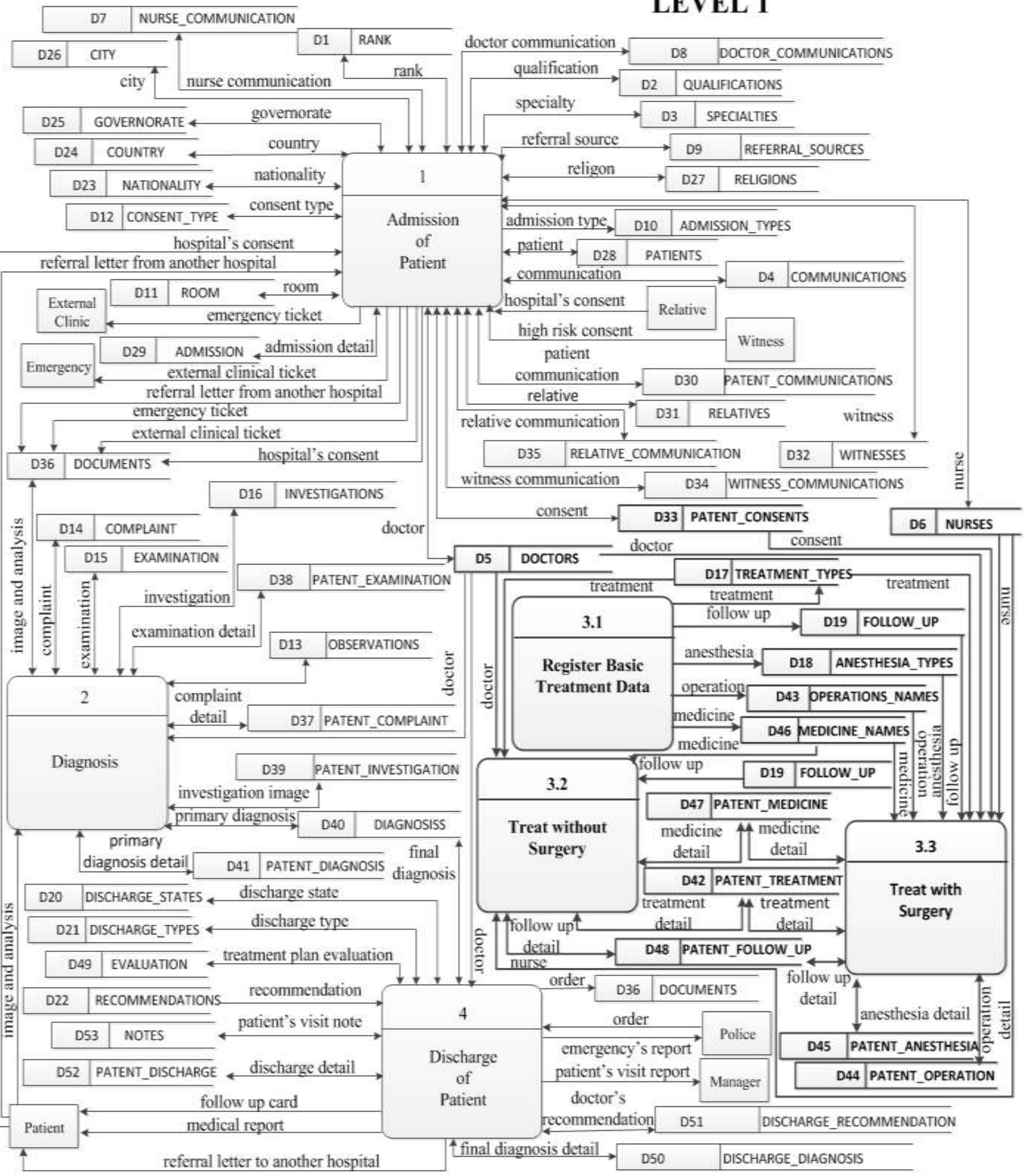

Figure 8 Viewing the details of process 3 by means of a fisheye view. 


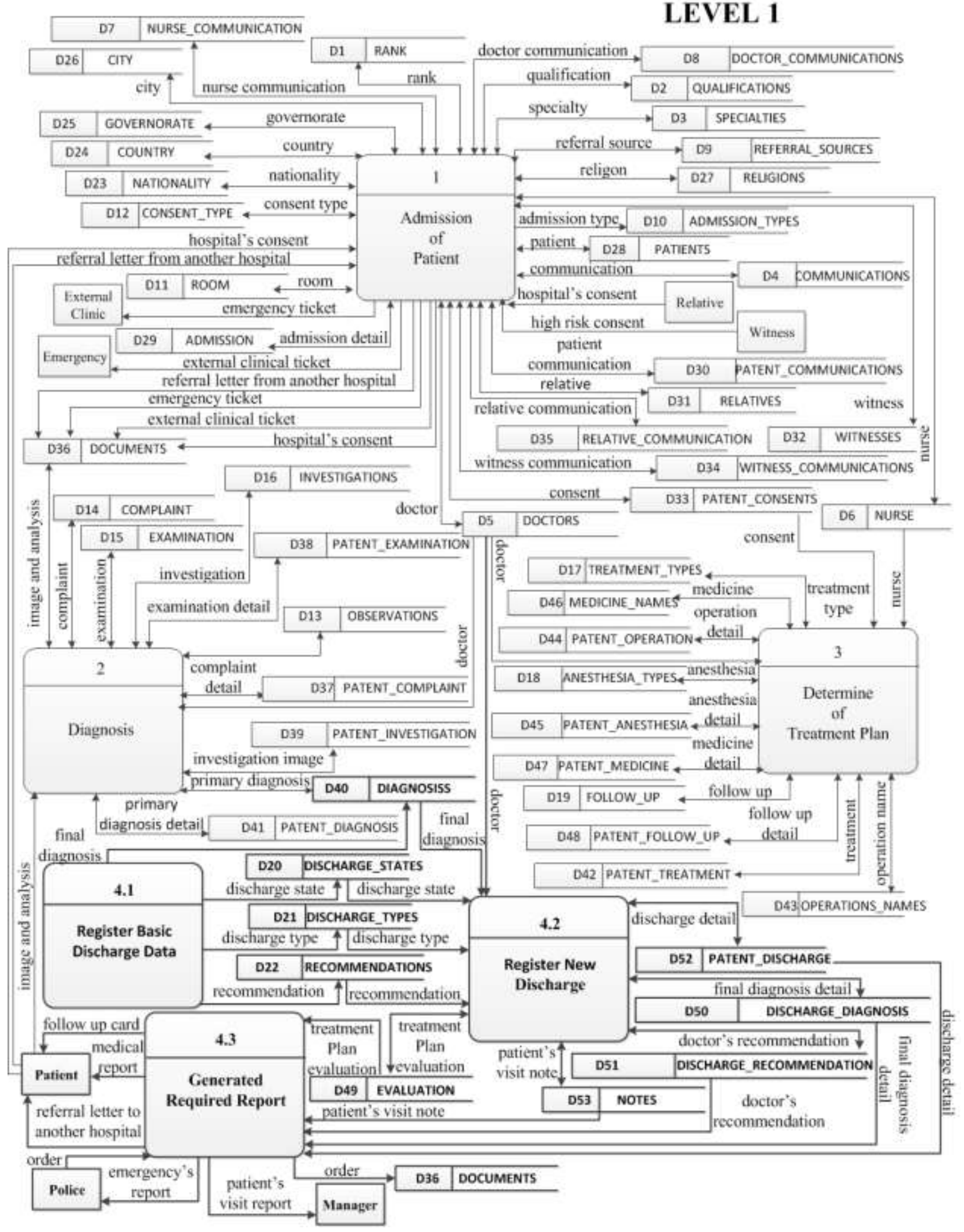

Figure 9 Viewing the details of process 4 by means of a fisheye view. 


\section{CONCLUSION}

This paper introduced fisheye lookup tools for DFD's as a context-aware representation of EMRS processes. The fisheye technique provides greater continuity between details and context than traditional representations; it has significant implications for indicating system analysis. These views lead to more effective analysis of the system in less time.

The proposed DFD's are very effective for enhancing communication between users and systems designers. It forms a good foundation to design EMRS which manages the data captured through the interfaces and created during patient's visits. This helps in providing the medical team with a secure, and time effective medical care that help in introducing and improving medical care in hospitals. Medical team will interact with the expert system using interfaces, which allow for the easy manipulating of data. Expert system stores in the knowledge base all the medical history, the descriptied medication , and the cumulative effect of therapy. The complexity of fisheye algorithms is proportional to the square root of $n$, where $n$ is number of scanned attributes. While the complexity of plant scanning is proportional to $n$. This reflects the speed of handling specific data, which may be digital images, or alphabetic text reports. Fig 11, indicates the complexity of fisheye and plant algorithms.

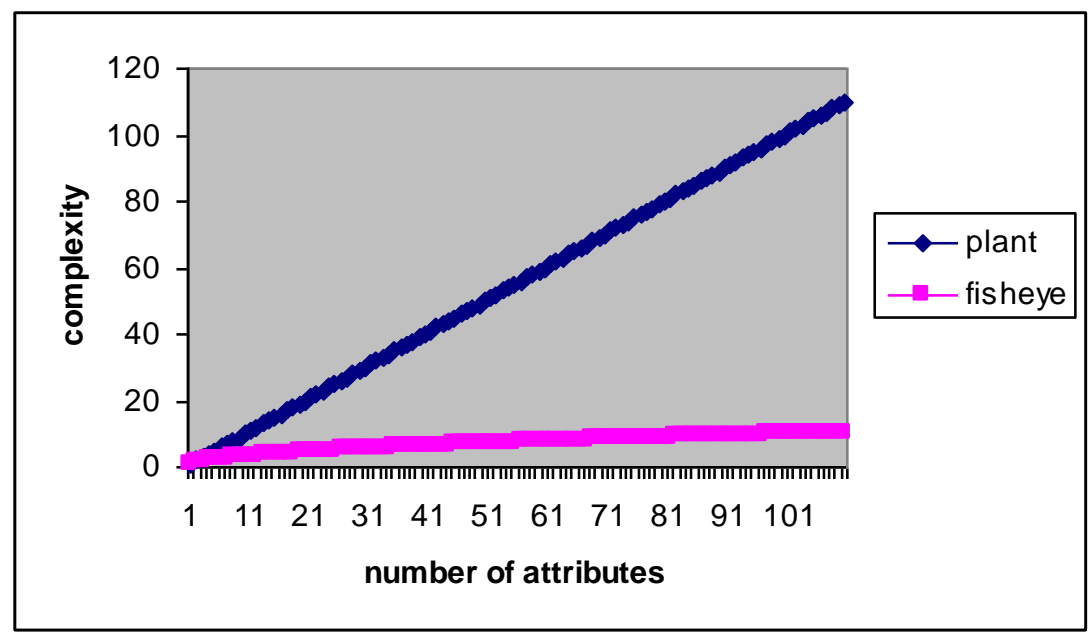

Fig 11, The Complexity of Fisheye and Plant Algorithms

\section{REFERENCES}

1. Agarwal VV., "Understanding Relational Databases", Beginning C\# 5.0 Databases, Vidya Vrat Agarwal (2012).

2. Al-Mujaini A., Al-Farsi Y., Al-Maniri A., and Ganesh A., "Satisfaction and Perceived Quality of an Electronic Medical Record System in a Tertiary Hospital in Oman", Oman Medical Journal, Vol. 26, No. 5:324-328, DOI 10. 5001/omj.2011.81, Oman Medical Specialty Board (2011).

3. Feeley and Shine, "Access to the Medical Record for Patients and Involved Providers: Transparency Through Electronic Tools", Annals of Internal Medicine, Vol. 155, American College of Physicians (2011).

4. Flynn A., Pharm D., and Haines S., "Pharmacists' Requirement for Continuity of The Clinical Narrative in The Electronic Medical Record", Informatics Interchange, Am J Health-Syst Pharm, Vol. 69, DOI 10.2146/ajhp110592, (2012).

5. Fountas S., Wulfsohn D., Blackmore B., Jacobsen H., and Pedersen S., "A Model of Decision-Making and Information Flows for Information-Intensive Agriculture”, Agricultural Systems, Vol. 87, 192-210, Elsevier (2006).

6. Hiremath H., and Skibniewski M., "Object-Oriented Modeling of Construction Processes by Unified Modeling Language", Automation in Construction, Vol. 13 447-468, (2004).

7. Horning R., "Implementing an Electronic Medical Record with Computerized Prescriber Order Entry at a Critical Access Hospital", American Society of Health-System Pharmacists, Vol. 68, DOI 10.2146/ajhp110249, Commentary (2011).

8. Jones R., Mehta M., and McKinley R., "Medical Student Access to Electronic Medical Records in UK Primary Care", Education for Primary Care, Vol. 22: 4-6, Radcliffe (2011).

9. Kodali S., "The Design and Implementation of an E-Commerce Site for Online Book Sales", MSC. Thesis, Indiana University South Bend (2007).

10. Langer A., "Creating Requirement Documents Using Analysis Tools", Guide to Software Development, DOI: 10.1007/978-1-4471-2300-2_8, Springer (2012).

11. Lau F., Price M., Boyd J., Partridge C., Bell H., and Raworth R., "Impact of Electronic Medical Record on Physician Practice in Office Settings: A Systematic Review", BMC Medical Informatics and Decision Making (2012).

12. Ozgur T. and David S., "The impact of context-aware fisheye models on understanding business processes: An empirical study of data flow diagrams", Information \& Management, Vol. 44, 40-52, DOI:10.1016/j.im.2006.10.004, Elsevier (2007).

13. Sangjae L., and Ingoo H., "EDI Controls Design Support System Using Relational Database System", Decision Support Systems, Vol. 29, 169-193, Elsevier (2000).

14. Spönemann M., Fuhrmann H., Hanxleden R., and Mutzel P., "Port Constraints in Hierarchical Layout of Data Flow Diagrams", LNCS 5849, pp. 135-146, Springer (2010). 